\title{
Bakthtin e o ensino de língua materna no Brasil:
}

\author{
algumas perspectivas
}

\section{Maria Inês Batista Campos ${ }^{1}$}

\begin{abstract}
The purpose of this article is to examine the influence of Bakhtinian theory, in particular the concept of speech genre, in official documents of the Ministry of Education in Brazil intended for teachers in the public and private networks. In order to understand this very important impact of Bakhtin and the Circle, several aspects of how the works that were the hallmark of government guidance were received will be revisited. The outcome will be supplemented by analyzing a chapter of a textbook in the native language for high school students that deals with the concept of genre in teaching the production of argumentative texts.
\end{abstract}

Keywords: Speech Genres; Heteroglossia; Dialogism; Textbooks.

Resumo: Este artigo tem como objetivo examinar a influência da teoria bakhtiniana, em particular, o conceito do gênero de discurso, nos documentos oficiais do Ministério da Educação no Brasil dirigidos aos professores da rede pública e privada. A fim de compreender essa presença tão importante de Bakhtin e o Círculo, serão recuperados alguns aspectos da recepção das obras que marcaram as orientações governamentais. O resultado será complementado com a análise de um capítulo de livro didático de língua materna para alunos do ensino médio que aborda o conceito do gênero no ensino da produção de textos argumentativos.

Palavras-chave: Gêneros do discurso; plurilinguismo; dialogismo; livro didático.

\section{Considerações preliminares²}

O filósofo da linguagem, Mikhail Bakhtin, tornou-se muito conhecido, lido e citado entre professores de língua materna da escola básica brasileira e nos materiais didáticos, principalmente com seu ensaio póstumo "Os gêneros do discurso" (1979), escrito entre 1951-533. Esse sucesso ocorreu a partir dos anos 1990, quando foram mobilizados os conceitos de "língua", "linguagem", "texto", "gêneros do discurso" nas orientações oficiais

1 Docente dos Cursos de Graduação e Pós-Graduação em Letras da Universidade de São Paulo. Editora da Revista Científica Linha d'Água do Programa de Pós-Graduação em Filologia e Língua Portuguesa - USP. Pós-Doutorado na Universidade de Vincennes- Saint Denis - Paris VIII.

2 Esta pesquisa faz parte do Projeto Letramentos, ensino, memória: a análise dialógica do discurso, e integra pós-doutorandos, doutorandos, bolsistas de mestrados e Iniciação Científica na linha de pesquisa "Linguística Aplicada do Português".

3 Em português, o ensaio foi publicado na coletânea Estética da criação verbal, de M. M. BAKHTIN (São Paulo: Martins Fontes, 1992), tradução a partir da edição francesa Esthétique de la création verbale. Traduit du russe par Alfreda Aucouturier, préface de Tzvetan Todorov. (Paris: Gallimard, 1984). 
para regulamentar o ensino de língua portuguesa para o nível fundamental e médio do país. Segundo Rodrigues (2006) ${ }^{4}$, as ideias do Círculo de Bakhtin

“[...] tem impulsionado as discussões teóricas e os desenvolvimentos pedagógicos na área de ensino de línguas a partir de meados da década de 1980. [...] Mesmo que o foco central de atenção do Círculo não tenha sido o ensino /aprendizagem de línguas, há em seus textos considerações a respeito da temática que surpreendem pela contemporaneidade". 5

O foco deste artigo incidirá nos textos de Bakhtin e Voloshinov que marcaram de maneira explícita ou implicitamente os documentos produzidos pelo Ministério da Educação (MEC) para implantar a reforma do ensino de língua materna em diferentes momentos políticos no Brasil. Na primeira parte, vamos contextualizar alguns aspectos da chegada das traduções de Bakhtin, a fim de situar como elas aportaram em terras brasileiras. Em seguida, analisar o percurso do conceito de gênero do discurso nos três documentos intitulados Parâmetros Curriculares Nacionais de Língua Portuguesa para o ensino fundamental $\left(1^{\circ}\right.$ e $2^{\circ} \mathrm{Ciclos}^{6} ; 3^{\circ}$ e $\left.4^{\circ} \mathrm{Ciclos}^{7}\right)$, daqui para frente PCNs, respectivamente publicados em 1997 e 1998 e, Orientações curriculares para o ensino médio: Linguagens, códigos e suas tecnologias ${ }^{8}$, publicado em 2006, uma versão revista dos Parâmetros Curriculares para o Ensino Médio? .

A influência da teoria bakhtiniana marca esses documentos dirigidos a professores dos vários níveis ${ }^{10}$, entretanto, também há diluição, omissão ou falta clareza quanto aos conceitos utilizados nos vários textos. Tais procedimentos acabam confundindo termos como "gêneros de texto" de Jean-Paul Bronckart (1999) ou Bernard Schneuwly como se fosse a mesma noção postulada por M. Bakhtin e o Círculo, ou misturando com "tipo de texto", de Jean-Michel Adam (1999) ${ }^{11}$. Em alguns momentos, ainda, levam a confusões como entender texto como sinônimo de gênero do discurso.

A título de exemplo dessa análise dos documentos, apresentaremos a análise de um capítulo de livro didático para o ensino médio ${ }^{12}$, com foco na atividade de produção de escrita com uma abordagem argumentativa. O intuito é discutir a mobilização dos conceitos de gêneros do discurso, tão valorizados no ensino e postos na Orientações curri-

4 Rosângela Hammes Rodrigues, pesquisadora de linguística aplicada, escreveu o artigo 'Os gêneros do discurso na perspectiva dialógica da linguagem: a abordagem de Bakhtin’, in J. L. Meurer et al. (eds.), Gêneros: teorias, métodos, debates. São Paulo: Parábola, 2005, pp.184-207.

5 R.H. Rodrigues, p. 153.

6 Brasil /Secretaria da Educação Fundamental. Parâmetros curriculares nacionais de Lingua Portuguesa: primeiro e segundo ciclos do ensino fundamental: língua portuguesa, (Brasília: MEC/SEF, 1997). Disponível em: http://portal.mec.gov.br/seb/arquivos/pdf/portugues.pdf. Acesso 29/10/2014.

7 Brasil / Secretaria da Educação Fundamental. Parâmetros curriculares nacionais de Língua Portuguesa: terceiro e quarto ciclos do ensino fundamental: língua portuguesa. (Brasília: MEC/SEF, 1998). Disponível em: http://portal.mec.gov.br/seb/arquivos/pdf/portugues.pdf. Acesso 29/10/2014.

8 Brasil /Secretaria da Educação Básica. Orientações Curriculares para o ensino médio: linguagens, códigos e suas tecnologias. Língua Portuguesa. Brasília: MEC/SEF, 2006.

9 Faz mais sentido analisar o segundo documento revisto, porque os conceitos foram aprofundados com relação ao primeiro documento (2000). As referências bibliográficas permaneceram inalteradas.

10 Uma boa discussão sobre o tema, consultar artigos de R. Rojo, 'Gêneros do discurso e gêneros textuais: questões teóricas e aplicadas', in J. L. Meurer et al. (eds.), Gêneros: teorias, métodos, debates (São Paulo: Parábola, 2005), pp.184-207; R. Rojo, 'Gêneros de discurso/texto como objeto de ensino de línguas: um retorno ao trivium?’, in I. Signorini, [Re]discutir texto, gênero e discurso. São Paulo: Parábola, 2008, pp.73-108.

11 J. M. Adam, Linguistique textuelle: Des genres de discours aux textes. Paris: Nathan, 1999.

12 A coleção selecionada para análise foi aprovada no Programa Nacional do Livro Didático (PNLD/EM) -2015. Disponível no Guia do Livro didático de Português. 
culares para o ensino médio a partir das relações entre os sujeitos das diferentes culturas e nas relações de poder. A teoria, entretanto, ao ser divulgada no ensino, parece voltar, muitas vezes, a aplicações de formas mecânicas do ensino da língua e as atividades didáticas propostas com leitura de textos, compreensão e produção escrita permanecem fragmentadas, distanciando-se da proposta teórico-metodológica defendida por Bakhtin e o Círculo. Antes de explorar o tratamento dado ao conceito de gêneros, vamos considerar o tempo-espaço das publicações mencionadas nos documentos analisados para entender como elas foram lidas particularmente nesse contexto.

\section{Alguns aspectos da recepção brasileira de Bakhtin}

Nos documentos governamentais do final dos anos 1990, dois livros são citados sob o nome de Bakhtin: Marxismo e filosofia da linguagem $^{13}(M F L)$ e Estética da criação verbal. Assim, o primeiro passo para abordar como essas fontes bibliográficas chegaram ao conhecimento dos professores de português e autores de livros didáticos é recuperar a cronologia das traduções no Brasil e especificamente o contexto sócio-histórico e político em que apareceram. MFL foi publicado no final da década de 1970, momento em que o país vivia sob o regime militar, começando um processo lento de redemocratização. "A situação política na educação era insatisfatória porque não havia vagas suficientes para os candidatos e à escola ficava a responsabilidade de preparar para o mercado de trabalho parte da demanda. [...] A preocupação do governo militar e da sociedade tecnocrata com o aprimoramento técnico era com a eficiência produtividade, o que exigia a formação de mão-de-obra técnica e especializada". ${ }^{14}$

Essa cena político-social ajuda a compreender o espaço de acolhimento dos pesquisadores para as ideias de Bakhtin/Voloshinov que chegavam naquele momento em terras brasileiras. Foi nessa realidade que a tradução de Marxismo e filosofia da linguagem apareceu em 1979 e ganhou espaço nos meios acadêmicos como explica Carlos Alberto Faraco, pesquisador da Universidade Federal do Paraná:

A descoberta de Voloshinov no fim da década de 1970 - entre outras ondas intelectuais funcionou como uma preciosa mão na roda, o que favoreceu a imediata sacralização do seu texto, sacralização que permanece até hoje. ${ }^{15}$

Nos documentos do Ministério da Educação, no entanto, a citação desse livro manteve as mesmas dificuldades da divulgação dos textos de Bakhtin, pelo menos no Ocidente. Vamos levantar três delas. A primeira dificuldade é quanto à autoria de Marxismo e filosofia da linguagem, que ficou atribuída somente a Bakhtin, embora os dois nomes (Bakhtin/ Voloshinov) tenham aparecido na capa da edição brasileira. A segunda refere-se à citação incompleta do título, faltando o importante subtítulo "Problemas fundamentais do método sociológico na Ciência da Linguagem”. Tal procedimento revela o apagamento do método sociológico da linguagem proposto pelos teóricos russos. De maneira geral,

13 Na bibliografia, Marxismo e filosofia da linguagem está atribuído a Bakhtin, mas a edição brasileira, seguindo a francesa, apresenta os nomes de M.M.Bakhtin e de V.Volochínov na capa.

14 A. C. C. Visioli, Política de ensino de língua portuguesa e prática docente. Dissertação de Mestrado. (Maringá-Paraná: UEM, 2004), p. 32.

15 C. A. Faraco, 'Voloshinov: um coração humboldtiano?' in C. A. Faraco et al. (eds.), Vinte ensaios sobre Mikhail Bakhtin (Petrópolis, Rio de Janeiro: Vozes, 2006), pp.125-126. 
as alusões a temas como ideologia, sujeito social, interação verbal presentes nos textos oficiais, muitas vezes, se confundem com conceitos advindos da Linguística Textual ou da Psicologia Cognitiva. Por fim, o desafio maior dos escritos bakhtinianos envolve as imprecisões da tradução e a "falta de uniformidade terminológica. [...] Cada edição brasileira tem um tradutor diferente, além de derivar ora do original russo, ora da tradução francesa, recorrendo, às vezes, à tradução inglesa [...]". ${ }^{16}$ Nesse sentido, Faraco afirmou:

[no Brasil] Além de não poucos problemas de tradução, o pensamento do Círculo, com bastante frequência e durante muitos anos, foi identificado quase exclusivamente ao livro Marxismo e filosofia da linguagem, o primeiro a ser publicado em português. ${ }^{17}$

Em 1992, a coletânea Estética da criação verbal ${ }^{18}$ foi publicada no Brasil. A sociedade brasileira vivia um período de mudanças das políticas nacionais, entre elas a ampliação ao acesso da população ao Ensino Fundamental, médio e universitário. Nessa transformação do ensino, o conceito bakhtiniano de gêneros do discurso tornou-se um caminho para as exigências de se pensar em novas formas de leitura e escrita.

O livro, traduzido a partir da edição francesa, teve sucesso imediato, e passou a ser citado nos documentos pedagógicos a partir de 1995 devido ao ensaio inacabado "Os gêneros do discurso". ${ }^{19}$ A segunda tradução a partir do original russo só saiu em 2003 e trouxe quatro textos que não estavam na edição anterior, o que representou uma significativa contribuição para a compreensão do conjunto da obra de Bakhtin. Foram incluídos os textos "Arte e responsabilidade" ["Art and Answerability"] ${ }^{20}$, "A respeito de Problemas da obra de Dostoiévski" ["Towards a Reworking of the Book on Dostoevsky"] ${ }^{21}$, "Reformulação do livro sobre Dostoiévski" [Three Fragments from the 1929 Edition Problems of Dostoevsky's Art"] 22 e "Conferências sobre história da literatura russa" ["From Lectures on the History of Russian Literature: Viacheslav Ivanov"] ${ }^{23}$, 1920. Embora essa edição brasileira já estivesse em circulação no momento em que o documento do ensino médio foi elaborado, os organizadores mantiveram a citação da edição de 1992, demonstrando que a concepção intelectual francesa de fontes estruturalistas da primeira tradução perdurou na perspectiva dos pesquisadores organizadores e dos professores envolvidos no projeto oficial.

Dos textos mais conhecidos da coletânea, está o ensaio "Os gêneros do discurso". Um breve resumo para focar o que concerne ao ensino da língua materna. Dividido em duas partes, logo no início Bakhtin apresenta a definição de gênero do discurso. A segunda parte intitulada "O enunciado como unidade da comunicação discursiva. Diferença entre

16 Geraldo Tadeu Souza, Introdução à teoria do enunciado concreto do círculo Bakhtin/Volochinov/Medvedev (São Paulo: Humanitas, 1999), p. 42.

17 C. A. Faraco, Linguagem \&diálogo: as ideias linguísticas do círculo de Bakhtin (São Paulo: Parábola, 2009), p.15.

18 Título em russo Estetika slovesnogo tvorchestva (1979, material de arquivos publicado em Moscou pela editora Iskusstvo).

19 English translation, M.M. Bakhtin, Speech Genres \& Other Late Essays. Trans. Bern W. Mc Gee, eds. C. Emerson; M. Holquist (Austin: University of Texas Press, 1986), pp. 159-72.

20 English translation, M.M.Bakhtin. Art and Answerability. Early Philosophical Essays by M.M. Bakhtin, trans. Vadim Liapunov (Austin: University of Texas Press, 1990), pp.1-3.

21 English translation: second section as appendix to Problems of Dostoevsky's Poetics, Trans. C. Emerson. Minneapolis: University of Minnesota, 2006, pp. 283-302.

22 English translation: Appendix I to Problems of Dostoevsky's Poetics, trans. C. Emerson. Minneapolis: University of Minnesota, 2006, pp. 275-82.

23 In M.M.Bakhtin, Estetika slovesnogo tvorchestva, pp. 394-403. 
essa unidade e as unidades da língua (palavras e orações)" "24 trata de distinguir oração e enunciado dentro de uma ordem teórico-metodológica para entender os gêneros do discurso nas várias esferas da atividade humana. A oração, unidade do sistema gramatical abstrato, é posta em contraste com o enunciado, unidade do acontecimento, do singular, do irreproduzível, produto da interação social, pois o discurso só existe na forma de enunciados concretos. Bakhtin defende a constituição de duas disciplinas interligadas, mas metodologicamente separadas para o estudo da linguagem:

Esses dois pontos de vista sobre o mesmo fenômeno concreto da língua não devem ser mutuamente impenetráveis nem simplesmente substituir mecanicamente um ao outro, devendo, porém, combinar-se organicamente (na sua mais precisa distinção metodológica) com base na unidade real do fenômeno da língua. Só uma concepção profunda da natureza do enunciado e das peculiaridades dos gêneros discursivos pode assegurar a solução dessa complexa questão metodológica. ${ }^{25}$

A análise da oração orienta-se na busca do que na língua é sistemático, organizado em estruturas, operando com categorias pré-definidas, exatamente o que tem subsidiado tradicionalmente o ensino de língua materna. $\mathrm{O}$ enunciado concreto apoia-se em outras bases. Comporta o já-dito, as antecipações, as relações entre, no mínimo, dois sujeitos sociais. O estudo da linguagem, a partir do enunciado concreto, introduz uma noção de texto, como um acontecimento, uma resposta a outros textos, que tratam do mesmo objeto do discurso, e, com os quais se relaciona, ao mesmo tempo, que é uma resposta orientada ao seu interlocutor. Cada texto pressupõe um sistema convencional, isto é uma língua, mas, exatamente, por ser único, irreproduzível, lugar dos sentidos, sua reprodução por um sujeito é sempre um acontecimento novo, "é um elo na cadeia da comunicação discursiva" ${ }^{26}$, do grande e inacabado diálogo.

A partir desses pressupostos teóricos, Bakhtin propõe um estudo da linguagem enquanto atividade comunicativa, não compreendida somente como forma ou classificação, mas como um campo interativo formado por gêneros de diferentes esferas da atividade humana. Ao abordar os signos verbais, seja na sua dimensão oral ou escrita, a orientação para o outro e o diálogo entre consciências estabelecem como elementos indispensáveis aos estudos da linguagem.

A teoria dos gêneros não está somente nesse texto, mas perpassa várias obras de Bakhtin e o Círculo, permitindo operar metodológica e didaticamente com o uso da linguagem na atividade humana. Como afirma Brait,

a cada conceito mobilizado a partir das propostas bakhtinianas é preciso levar em conta que ele forma, com os demais uma rede e que dificilmente poderá dela dissociar-se. No caso de gênero discursivo, interferem também os conceitos de plurilinguismo, dialogismo, polifonia, responsabilidade, tom, etc. ${ }^{27}$

24 M. M. Bakhtin. Os gêneros do discurso, in Estética da criação verbal. Trad. Paulo Bezerra. São Paulo: Martins Fontes, 2003, p. 270.

25 Bakhtin, p. 269.

26 Bakhtin, p. 289

27 B. Brait. 'PCNs, gêneros e ensino de língua: faces discursivas da textualidade', in R. Rojo (ed.), A prática de linguagem em sala de aula (São Paulo: EDUC, Campinas: Mercado de Letras, 2000), p. 20. 
A consequência dessa abordagem teórica dos gêneros do discurso é que para incorporá-la ao ensino de língua materna é necessário entendê-la de modo diferente das teorias tradicionais dos gêneros literários ligados à concepção aristotélica, e também é preciso não operar com categorias pré-estabelecidas ou com modelos definidos fora das interações sociais.

\section{O conceito de gêneros nos documentos do Ministério da Educação (MEC)}

Nos Parâmetros Curriculares Nacionais de Língua Portuguesa (PCNs) para os dois ciclos $\left(1^{\circ} / 2^{\circ}\right.$ e $\left.3^{\circ} / 4^{\circ}\right)$, o conceito de gêneros impera como um organizador de currículo, estruturando o funcionamento da linguagem oral, escrita e de literatura nas várias esferas de circulação. Nas palavras de Gomes-Santos, "o conceito de gênero é, nesse documento particular, eleito como conceito-chave para a operacionalização do ensino de português" ${ }^{28}$, na busca de problematizar práticas do ensino tradicional.

Essa didatização pode ser surpreendida na consulta ao longo dos dois textos governamentais. Os organizadores, no entanto, partem de abordagens teóricas concorrentes: gêneros de texto e gêneros do discurso e fazem poucas citações bibliográficas, de modo que os conceitos são flagrados por meio de paráfrases. Na introdução do texto para o $1^{\circ}-2^{\circ} \mathrm{Ci}$ clos, depreende-se a abordagem do conceito por meio de uma menção colocada em nota de rodapé: "O termo gênero é utilizado aqui como proposto por Bakhtin e desenvolvido por Bronckart e Schneuwly". ${ }^{29}$ Entretanto, a teoria dos gêneros do discurso centra-se em aspectos sócio-históricos e a teoria dos gêneros textuais foca a composição da materialidade linguística do texto, filiada ao interacionismo sociodiscursivo. As fontes do conceito de gêneros presente nas orientações governamentais estão relacionadas à abordagem didática dos pesquisadores da Universidade de Genebra (Schneuwly; Dolz, 1996;1998), em versões preliminares citadas no documento brasileiro, mas não publicadas.

Na primeira parte dos PCNs $3^{\circ} / 4^{\circ}$ Ciclos, a seção "Condições para o tratamento do objeto de ensino: o texto como unidade e a diversidade de gêneros" apresenta uma retomada de conceitos bakhtinianos - texto e gênero - sem mencionar as fontes primárias, $o$ que acaba por descontextualiza-los do conjunto da teoria de Bakhtin e o Círculo, recolocando-o no âmbito do ensino de língua portuguesa. O que se lê é:

Todo texto se organiza dentro de determinado gênero em função das intenções comunicativas, como parte das condições de produção dos discursos, as quais geram usos sociais que os determinam. Os gêneros são, portanto, determinados historicamente, constituindo formas relativamente estáveis de enunciados disponíveis na cultura. São caracterizados por três elementos: conteúdo temático: o que é ou pode tornar-se dizível por meio do gênero; construção composicional: estrutura particular dos textos pertencentes ao gênero; estilo: configurações específicas das unidades de linguagem derivadas, sobretudo, da posição enunciativa do locutor; conjuntos particulares de sequências que compõem o texto etc. ${ }^{30}$

28 S. Gomes-Santos, A questão do gênero no Brasil: Teorização acadêmico-científica e normatização oficial. Tese de doutorado. (Campinas, Instituto de Estudos da Linguagem, Universidade Estadual de Campinas/ Unicamp, 2004), p. 152.

29 Brasil/Secretaria da Educação Fundamental. Parâmetros curriculares nacionais de Língua Portuguesa: primeiro e segundo ciclos do ensino fundamental: língua portuguesa. (Brasília: MEC/SEF, 1997), p.26.

30 Brasil / Secretaria da Educação Fundamental. Parâmetros curriculares nacionais de Língua Portuguesa: terceiro e quarto ciclos do ensino fundamental: língua portuguesa. (Brasília: MEC/SEF, 1998), pp. 21-22. 
Ao comparar esse fragmento com o ensaio bakhtiniano, constata-se que o excerto está diretamente calcado nele, como se depreende do trecho a seguir, embora os organizadores tenham omitido sua origem no documento, fazendo parecer que a autoria é da instituição que assina ("Brasil. Secretaria de Educação Fundamental”):

Todos esses três elementos - o conteúdo temático, o estilo, a construção composicional estão indissoluvelmente ligados no todo do enunciado e são igualmente determinados pela especificidade de um determinado campo da comunicação. Evidentemente, cada enunciado particular é individual, mas cada campo de utilização da língua elabora seus tipos relativamente estáveis de enunciados, os quais denominamos gêneros do discurso. ${ }^{31}$

Na primeira parte dos PCNs "Que escrita cabe à escola ensinar", aparecem duas questões centrais: gênero assume o estatuto de objeto de ensino e texto funciona como unidade do ensino, de maneira que o texto se torna fonte de referência que amplia o repertório do aluno.

Todo texto pertence a um determinado gênero, com uma forma própria, que se pode aprender. Quando entram na escola, os textos que circulam socialmente cumprem um papel modelizador, servindo como fonte de referência, repertório textual, suporte da atividade intertextual32. A diversidade textual que existe fora da escola pode e deve estar a serviço da expansão do conhecimento letrado do aluno. ${ }^{33}$

Os organizadores estabelecem um ensino de português baseado na diversidade de textos e focam no trabalho com a intertextualidade. Mais uma vez constata-se uma outra diluição da concepção bakhtiniana de texto como enunciado. Ao introduzir o termo "intertextualidade", palavra empregada pela semioticista búlgara Julia Kristeva, em 1967, na revista francesa Critique com o sentido de se referir a um texto que absorve outro texto, muda o sentido de enunciado concreto. Nos escritos de Bakhtin, a questão que se apresenta é a do dialogismo nos discursos, examinada sob uma perspectiva bem diferente: trata da organização do plurilinguismo, do discurso citado, dos gêneros intercalados. Ao reler o ensaio "O discurso no romance", vamos encontrar o conceito de "construção híbrida", distanciando-se da abordagem linguística na qual o texto é tratado como produto meramente linguístico. Bakhtin explica:

What we are calling a hybrid construction is an utterance that belongs, by its grammatical (syntactic) and compositional makers, to a single speaker, but that actually contains mixed within it two utterances, two speech manners, two styles, two "languages", two semantic and axiological belief systems. ${ }^{34}$

31 M.M.Bakhtin, Os gêneros do discurso, in Estética da criação verbal. Trad. Paulo Bezerra. (São Paulo: Martins Fontes, 2003), p. 261-262.

32 Destaque da autora do artigo, a fim de ressaltar uma nova confusão que se estabelece entre gêneros do discurso, texto e intertextualidade, como se pode notar pelas sugestões do documento, afastando das posições teóricas bakhtinianas.

33 Brasil /Secretaria da Educação Fundamental. Parâmetros curriculares nacionais de Língua Portuguesa: primeiro e segundo ciclos do ensino fundamental: língua portuguesa. (Brasília: MEC/SEF, 1997), p.34.

34 M.M.Bakhtin, Discourse in the Novel, in Michael Holquist (edited), The Dialogic Imagination: Four Essays by M.M.Bakhtin, trad. Caryl Emerson (et al.), (Austin: University of Texas Press, 1981), p. 110. (Tradução em português M. M. Bakhtin, Discurso no romance, Questões de literature e de estética: a teoria do romance. Trad. Equipe Aurora Fornoni Bernadini. (São Paulo: Unesp, 1998), p. 110. 
Passamos a observar a segunda parte dos Parâmetros Curriculares de Língua Portuguesa que tem como foco a prática do ensino de língua portuguesa. Os documentos apresentam orientações muito semelhantes tanto a professores de séries iniciais como finais. Na seção "Tratamento didático dos conteúdos", o conceito "gêneros do discurso" é explorado como conteúdo e pode-se detectar a seguir que o termo é adotado como organizador didático.

\begin{abstract}
Gêneros discursivos
Gêneros adequados para o trabalho com a linguagem oral: contos (de fadas, de assombração, etc.), mitos e lendas populares; poemas, canções, quadrinhas, parlendas, adivinhas, trava-línguas, piadas; saudações, instruções, relatos; entrevistas, notícias, anúncios (via rádio e televisão); seminários, palestras.

Gêneros adequados para o trabalho com a linguagem escrita: receitas, instruções de uso, listas; textos impressos em embalagens, rótulos, calendários; cartas, bilhetes, postais, cartões (de aniversário, de Natal, etc.), convites, diários (pessoais, da classe, de viagem, etc.); quadrinhos, textos de jornais, revistas e suplementos infantis: títulos, lides, notícias, classificados, etc.; anúncios, slogans, cartazes, folhetos; parlendas, canções, poemas, quadrinhas, adivinhas, trava-línguas, piadas; contos (de fadas, de assombração, etc.), mitos e lendas populares, folhetos de cordel, fábulas; textos teatrais; relatos históricos, textos de enciclopédia, verbetes de dicionário, textos expositivos de diferentes fontes (fascículos, revistas, livros de consulta, didáticos, etc.). ${ }^{35}$
\end{abstract}

Esse fragmento estabelece o conceito de gêneros fora das condições sócio-históricas dos textos e das esferas de circulação e de recepção, reduzindo as formas composicionais, tema e estilo a aspectos exclusivamente linguísticos. Essa maneira de utilização e aplicação do conceito bakhtiniano perde sua proposta teórico-metodológica. Como afirma Voloshinov:

“[...] the task of understanding does not basically amount to recognizing the form used, but rather to understanding it in a particular, concret context, to understanding its meaning in a particular utterance, i.e., it amounts to understanding its novelty and not to recognizing its identity". ${ }^{36}$

Finalmente, em Orientações curriculares para o ensino médio: linguagens, códigos e novas tecnologias (2006) ${ }^{37}$, algumas mudanças se instalam na composição do documento que passam a ter como base teórica explicitamente a Linguística textual. No entanto, os consultores do Ministério da Educação (acadêmicos brasileiros reconhecidos no país) mantêm entre as referências bibliográficas a coletânea Estética da criação verbal, mas excluem Marxismo e filosofia da linguagem. Tal procedimento indica não só mudança conceitual nas orientações, mas também na forma prática de propor o ensino de língua portuguesa para o ensino médio.

35 Brasil /Secretaria da Educação Fundamental. Parâmetros curriculares nacionais de Língua Portuguesa: primeiro e segundo ciclos do ensino fundamental: língua portuguesa. (Brasília: MEC/SEF, 1997), pp.111-2.

36 V. N. Vološinov, Marxism and the Philosophy of Language. Trans. by L. Matejka; I.R.Titunik. (Cambridge, Massachusetts: Harvard University Press, 1973), p.68.

37 Brasil. Ministério da Educação. Secretaria de Educação Básica. Orientações Curriculares Nacionais para o Ensino Médio. Linguagens, códigos e suas tecnologias. (Brasília: Ministério da Educação; Secretaria da Educação Básica, 2006). Disponível portal.mec.gov.br/seb/arquivos/pdf/book_volume_01_internet.pdf. 
Ao percorrer as mais de trinta páginas do capítulo "Conhecimentos de língua portuguesa", pode-se notar o emprego de "gêneros discursivos/ gêneros do discurso" comparecendo bem distante da teoria de Bakhtin. No trecho a seguir retirado da segunda seção "A língua portuguesa no contexto do ensino médio", encontra-se, de forma implícita, a concepção bakhtiniana (relação dinâmica entre produção, circulação e recepção de textos) em diálogo com outras formas de abordar o processo interacional.

Prática de ensino e de aprendizagem da língua portuguesa como língua materna [...] será apontada a importância de se abordarem as situações de interação considerando-se as formas pelas quais se dão a produção, a recepção e a circulação de sentidos. ${ }^{38}$

A seguir, dois fragmentos do documento que se encontram da quinta seção "Organização curricular e procedimentos metodológicos de abordagem dos conteúdos" retomam o texto como objeto privilegiado de ensino e a delimitação dos conteúdos são organizadas nos agrupamentos de textos, isto é, na materialidade dos gêneros discursivos:

O que se propõe é que, na delimitação dos conteúdos, as escolas procurem organizar suas práticas de ensino por meio de agrupamentos de textos, segundo recortes variados, em razão das demandas locais, fundamentando-se no princípio de que o objeto de ensino privilegiado são os processos de produção de sentido para os textos, como materialidade de gêneros discursivos, à luz das diferentes dimensões pelas quais eles se constituem. ${ }^{39}$

[...] É pertinente conferir à noção de conteúdo programático um sentido ligado diretamente à ideia de que os conteúdos da área de Língua Portuguesa podem figurar como elementos organizadores de eixos temáticos em torno dos quais serão definidos, pela escola, os projetos de intervenção didática que tomarão como objeto de ensino e de aprendizagem tanto as questões relativas aos usos da língua e suas formas de atualização nos eventos de interação (os gêneros do discurso) como as questões relativas ao trabalho de análise linguística (os elementos formais da língua) e à análise do funcionamento sociopragmático dos textos (tanto os produzidos pelo aluno como os utilizados em situação de leitura ou práticas afins). ${ }^{40}$

As indicações das Orientações Curriculares para o Ensino Médio de Língua Portuguesa encerram um trabalho em relação ao gênero, usando a expressão gênero discursivo na perspectiva de gêneros textuais. Embora as consultoras afirmem tomar a linguagem como constitutiva do sujeito, a leitura e a escrita são tratadas como ferramentas. Na perspectiva teórica de Bakhtin e o Círculo, essa orientação torna-se incoerente uma vez que a concepção constitutiva da linguagem se dá na interação social, realizada por meio de enunciados concretos e não comporta a ideia de língua como ferramenta ou instrumento a ser utilizado ou ensinado na escola.

Na terceira seção "Concepção de língua e linguagem e práticas de ensino" desse capítulo, o conceito de texto é abordado na perspectiva interacionista e Bakhtin está associado a outras teorias numa enumeração posta em nota de rodapé:

38 Brasil. p. 19.

39 Brasil. p. 36.

40 Brasil. p. 36. 
Está-se referindo aqui tanto à contribuição de estudos desenvolvidos por essa vertente no escopo da Linguística, os quais envolvem estudiosos como Hymes, e na Filosofia da Linguagem, como Bakhtin, na Etnometodologia e Sociologia, como Goffman, na Psicologia, como Bronckart e na educação, como Schneuwly, quanto aos que se encontram no âmbito da Psicologia do Desenvolvimento com é o caso de Vygotsky e seus seguidores. ${ }^{41}$

Entendendo que os interlocutores desse documento são professores do ensino básico, essa enumeração apresenta-se problemática, confundindo-os com temas que eles nem sempre tem domínio específico e que pouco ajudam efetivamente na sua prática docente. $\mathrm{O}$ acesso de muitos docentes a alguns conceitos de Bakhtin e o Círculo se dá, num primeiro momento, por meio desses documentos oficiais estabelecidos para todo o país. Assim, as propostas curriculares, às vezes, são pouco esclarecedoras das concepções bakhtinianas de linguagem, plurilinguismo, dialogismo, gêneros do discurso.

Se é verdade que Bakhtin e o Círculo não tiveram como foco principal o ensino/ aprendizagem de línguas, também nos surpreendemos com algumas considerações significativas que apontam para uma possível metodologia de ensino de língua materna, que apresentam o enunciado concreto e o contexto sócio-histórico-ideológico em que foram engendrados como constitutivo

A língua materna - sua composição vocabular e sua estrutura gramatical - não chega ao nosso conhecimento a partir de dicionários e gramáticas mas de enunciações concretas que nós mesmos ouvimos e nós mesmos reproduzimos na comunicação discursiva viva com as pessoas que nos rodeiam. Nós assimilamos as formas da língua somente nas formas das enunciações e justamente com essas formas. As formas da língua e as formas típicas dos enunciados, isto é, os gêneros do discurso, chegam à nossa experiência e à nossa consciência em conjunto e estreitamente vinculadas. Aprender a falar significa aprender a construir enunciados (porque falamos por enunciados e não por orações isoladas e, evidentemente, não por palavras isoladas). Os gêneros do discurso organizam o nosso discurso quase da mesma forma que o organizam as formas gramaticais (sintáticas). ${ }^{42}$

What is central to all these methods is that students become acquainted with some word only through the presentation of a variety of contexts in which that word figures. [...] To put it briefly, under a sound and sensible method of practical instruction, a form should be assimilated not in its relation to the abstract system of the language, i.e., as a self-identical form, but in the concrete structure of utterance, i.e., as a mutable and pliable sign. ${ }^{43}$

Comparando os três documentos, isto é, os $P C N s$ de $1^{\circ}$ e $2^{\circ}$ ciclos e $3^{\circ}$ e $4^{\circ}$ ciclos e as Orientações Curriculares do Ensino Médio, no tempo-espaço em que foram produzidos -1997- 2006, observa-se que as orientações partiram do conceito bakhtiniano de gênero do discurso, mas na prática se operacionalizaram em atividades preestabelecidas de estudos de leitura e de escrita para os alunos das escolas brasileiras, muito distante da concepção de Bakhtin e o Círculo em torno da linguagem e do enunciado concreto. A título de exemplificação, apresentaremos uma atividade em livro didático de língua portuguesa que solicita aos alunos do ensino médio uma produção escrita.

41 Brasil. p. 23.

42 Bakhtin, Os gêneros do discurso, in Estética da criação verbal. Trad. Paulo Bezerra. (São Paulo: Martins Fontes, 2003), p. 282-283.

43 V.N.Vološinov, Marxism and the Philosophy of Language. Translated by Ladislav Matejka and I.R.Titunik, (Cambridge, Massachussets: Harvard University Press, 1973), p. 69. 


\section{O gênero do discurso no livro didático de português para o ensino médio}

Nesta última seção, o objetivo é apresentar o tratamento dado ao conceito gênero do discurso em Português: Linguagens $(2013)^{44}$, livro didático escrito em coautoria por Willian Roberto Cereja e Thereza Cochar Magalhães, uma das obras mais escolhidas pelos professores da rede pública e privada. Essa coleção, aprovada pelo Programa Nacional do Livro Didático para o Ensino Médio ${ }^{45}$ (2015), baseia-se no conceito de gêneros do discurso segundo Bakhtin para organizar o percurso teórico-metodológico do ensino de leitura e práticas de produção escrita. Organizada em três volumes, cada livro traz conteúdos de Literatura, Gramática e Produção de texto. Abordaremos primeiro como o "Manual do Professor" fornece subsídios teóricos para que o professor possa desenvolver suas aulas com os gêneros, em seguida, apresentaremos o resultado da análise de apenas uma atividade exemplar de produção escrita do gênero carta do leitor.

No "Manual do Professor", há uma seção "Produção de Textos" com referencial teórico intitulado "O que são gêneros do discurso"? 46 e nela os autores apresentam o pensador russo e sua teoria de maneira sucinta. As características dos gêneros são discutidas em duas páginas a partir da ideia bakhtiniana de que "todos os textos que produzimos, orais ou escritos, apresentam um conjunto de características relativamente estáveis, tenhamos ou não consciência delas" ${ }^{47}$. Em seguida, a subseção "gênero textual como ferramenta"48, faz referência aos estudos do Grupo de Didática de Francês Língua Materna da Universidade de Genebra (Joaquim Dolz e Bernard Schneuwly). Segundo as orientações de Cereja e Magalhães, o conceito bakhtiniano de "gêneros discursivos" é sinônimo de "gênero textual", compreendendo que a aprendizagem da produção textual "deva se dar em espiral, isto é, que os gêneros devam ser periodicamente retomados e seu estudo aprofundado e ampliado"49. Apresenta uma proposta curricular baseada no trabalho de Dolz, Pasquier e Schneuwly, citando uma tradução não publicada. Com essas explicações, a abordagem retoma de forma semelhante às diretrizes oficiais $(P C N s)$, não se desvencilhando da confusão entre gêneros do discurso versus gêneros textuais e tipos de texto.

Passemos ao capítulo "A carta do leitor", destinado ao $3^{\circ}$ ano do ensino médio, para analisar como os autores fazem as transposições didáticas para a elaboração do texto argumentativo. Vamos considerar três fatores do gênero discursivo: a esfera jornalística, o encaminhamento linguístico-discursivo e o ponto de vista como marca avaliativa.

O conceito de gênero está retomado já na organização das duas seções: "trabalhando o gênero" e "produzindo a carta de leitor". No quadro abaixo, apresentamos uma síntese da estrutura do capítulo:

44 A obra foi aprovada pelo Programa nacional do livro didático do ensino médio -PNLD-EM 2015 (BRASIL, 2014) e está disponível para as escolas públicas e particulares brasileiras.

45 O Programa Nacional do Livro Didático para o Ensino Médio foi criado pelo Ministério da Educação a em 2005, visando estabelecer critérios de qualidade do material didático comprado e distribuído gratuitamente pelo governo.

46 W.R.Cereja; T.C. Magalhães, Português: Linguagens, (São Paulo: Saraiva, 2013), pp. 417-420.

47 Cereja, p. 417.

48 Cereja, p. 418.

49 Cereja, p. 420. 


\section{Capítulo 2}

A carta do leitor

\begin{tabular}{|c|c|c|}
\hline SEÇÕES & \multicolumn{2}{|l|}{ TEMAS/PROPOSTAS } \\
\hline Trabalhando o gênero & \multicolumn{2}{|c|}{$\begin{array}{l}\text { Carta do leitor 1: Moradora orgulhosa", retirada da revista de } \\
\text { divulgação científica Horizonte Geográfico } \\
\text { Carta do leitor2: Capa, U.V.B, Santos, SP, revista IstoÉ } \\
\text { Carta do leitor 3: Capa, F.F. revista IstoÉ } \\
\text { Carta do leitor 4: R.C., Revista Veja } \\
\text { Carta do leitor 5: S.M.R, Folha de S. Paulo (jornal) } \\
\text { Carta do leitor 6: H.A. C. Folha de S. Paulo (jornal) } \\
\text { Carta do leitor7: C.E.G. Revista Época }\end{array}$} \\
\hline \multirow[t]{3}{*}{$\begin{array}{l}\text { Produzindo a carta de } \\
\text { leitor }\end{array}$} & Proposta & $\begin{array}{l}1 \text { proposta de produção de carta, em } \\
\text { grupo, para publicar em jornal ou } \\
\text { revista }\end{array}$ \\
\hline & Planejamento do texto & $\begin{array}{l}7 \text { proposições de orientação quanto } \\
\text { à produção da escrita, quanto à } \\
\text { leitura, esfera de circulação e de } \\
\text { recepção }\end{array}$ \\
\hline & Revisão e reescrita & $\begin{array}{l}7 \text { tópicos referentes à estrutura } \\
\text { dos parágrafos, emprego da norma } \\
\text { padrão. }\end{array}$ \\
\hline & $\begin{array}{l}\text { Escrevendo com } \\
\text { coerência e coesão }\end{array}$ & A articulação de palavras e ideias \\
\hline
\end{tabular}

Fonte: Cereja; Magalhães, 2003.

Os autores apresentam uma diversidade de leitura de textos na esfera jornalística e as sete questões mantêm o caráter estrutural de identificação de temas, sem muitas dificuldades. É preciso destacar que há uma boa introdução de variados textos e não mais a apresentação de um modelo único de carta, o que mostra as transformações que o livro didático vem sofrendo desde o início dos anos 2000. Contudo, as perguntas relacionadas aos articuladores do texto são desconsideradas completamente assim como o encaminhamento discursivo, deixando os elementos de conexão para uma seção que vem depois do texto já produzido, revisto e reescrito.

A indefinição teórica postulada no "Manual do Professor" quanto ao conceito dos gêneros discursivos acaba tendo como consequência uma ausência nas atividades quanto aos vários elementos que não são explorados nas atividades, um deles é o estilo do autor e do gênero. Cereja e Magalhães escolhem a perspectiva de Dolz e Schneuwly do gênero como um instrumento didático e acabam se afastando da concepção dialógica e plurilingue de gênero discursivo. No Brasil, muitos textos do Círculo de Bakhtin foram traduzidos no final da década de 2000 e os autores dos livros didáticos não citam na bibliografia, por exemplo, a importante referência para o gênero do discurso da obra de Pável Nikoláievitch Medviédev (Círculo de Bakthin), O método formal nos estudos literários: introdução crítica a uma poética sociológica, tradução de Ekaterina Vólkova Américo e Sheila Camargo Grillo, em 2012 e Questões de estilística no ensino da língua, em 2013.

Essas traduções revelam o quanto é necessário reler os trabalhos do Círculo "para compreender o pensamento bakhtiniano, não se pode ignorar as bases de uma postura ino- 
vadora em relação à linguagem, desenvolvida pela contribuição dos diferentes membros do Círculo, em diferentes momentos históricos" ${ }^{50}$. Reafirmamos a necessidade de rever a concepção de gêneros do discurso no ensino médio, para levar o aluno a compreender os aspectos sociais e fundamentais da linguagem viva num todo orgânico na sua circulação dinâmica.

\section{Considerações finais}

Conforme proposta inicial, este artigo procurou mostrar como o gênero do discurso de Bakhtin e o Círculo é colocado nos documentos oficiais e no livro didático do ensino médio numa perspectiva que não atende às suas bases teóricas. Impõe-se concluir que os professores de língua materna estão habituados a propostas de atividades que acabam levando o aluno a ler o texto em si mesmo, procurando características de modo mecânico e abstrato, isto é, uma teoria de gêneros muito distinta da proposta pelos teóricos russos como Voloshinov, Medvedev e Bakhtin. Os estudos bakhtinianos dos gêneros do discurso assumem como ponto de partida o estudo do homem e da sua linguagem nas ciências humanas.

\section{Referências}

ADAM, J. M. Linguistique textuelle: Des genres de discours aux textes. Paris: Nathan, 1999.

BAJTÍN, M.M. Estética de la creación verbal. Trad. Tatiana Bubnova. Buenos Aires: Siglo XXI, 2002.

BAKHTIN, M. M. Os gêneros do discurso. In: Estética da criação verbal. Trad. do francês Maria Ermantina Galvão Gomes Pereira. São Paulo: Martins Fontes, 1992. . Os gêneros do discurso. In: Estética da criação verbal. Trad. do russo Paulo Bezerra. São Paulo: Martins Fontes, 2003.

. Speech Genres \& Other Late Essays. Trans. Bern W. Mc Gee, eds. C. Emerson; M. Holquist. Austin: University of Texas Press, 1986, pp. 159-72.

. Art and Answerability: Early Philosophical Essays by M.M. Bakhtin. Edited by Michael Holquist and Vadim Liapunov. Austin: University of Texas Press, 1990. . Arte e responsabilidade. Estética da criação verbal. Trad. Paulo Bezerra. São

Paulo: Martins Fontes, 2003.

. Second section as appendix to Problems of Dostoevsky's Poetics. Trans. C.

Emerson. Minneapolis: University of Minnesota, 2006, pp. 283-302.

. Appendix I to Problems of Dostoevsky's Poetics. Trans. C. Emerson.

Minneapolis: University of Minnesota, 2006, pp. 275-82.

. Discourse in the Novel. In: BAKHTIN, M. The Dialogic Imagination: Four Essays by M.M.Bakhtin. Michael Holquist (edited). Trad. Caryl Emerson (et al.). Austin: University of Texas Press, 1981.

. Discurso no romance. In: BAKHTIN, M. Questões de literatura e de estética: a teoria do romance. Trad. equipe Aurora Fornoni Bernadini. São Paulo: Unesp, 1998.

50 B. Brait, Voloshinov: diálogo entre língua e literatura, in Beth Brait, Literatura e outras linguagens, (São Paulo: Contexto: 2010), p. 19. 
. (VOLOCHÍNOV, V. N.). Marxismo e filosofia da linguagem: problemas

fundamentais do método sociológico na ciência da linguagem. Trad. Michel Lahud e Yara Frateschi Vieira. 9. ed. São Paulo: Hucitec, 2002 [1929].

BAKHTINE, M. Esthétique de la création verbale. Trad. du russe Alfreda Aucouturier, préface de Tzvetan Todorov. Paris: Gallimard, 1984.

BRAIT, B. PCNs, gêneros e ensino de língua: faces discursivas da textualidade. In: ROJO, R. (ed.). A prática de linguagem em sala de aula São Paulo: EDUC, Campinas: Mercado de Letras, 2000.

BRAIT, B. Voloshinov: diálogo entre língua e literatura. In: BRAIT, B. Literatura e outras linguagens. São Paulo: Contexto: 2010.

BRASIL. Ministério da Educação (MEC). Parâmetros curriculares nacionais de Língua Portuguesa: primeiro e segundo ciclos do ensino fundamental: língua portuguesa (PCNs). Brasília: MEC/Secretaria de Educação Fundamental, 1997. Available at: http:// portal.mec.gov.br/seb/arquivos/pdf/portugues.pdf. Acesso 29/10/2014.

BRASIL. Ministério da Educação (MEC). Parâmetros curriculares nacionais de Língua Portuguesa: terceiro e quarto ciclos do ensino fundamental: língua portuguesa. Brasília: MEC/SEF, 1998. Available at: http://portal.mec.gov.br/seb/arquivos/pdf/portugues.pdf. Acesso 29/10/2014.

BRASIL. Ministério da Educação (MEC). Orientações Curriculares para o Ensino Médio (OCEM). Brasília: MEC/Secretaria de Educação Básica, 2006.

BRASIL. Ministério da Educação (MEC). Guia de livros didáticos: PNLD- EM 2015:

Língua Portuguesa. Brasília: MEC/FNDE/Secretaria de Educação Básica, 2014.

CEREJA; W. R.; MAGALHÃES, T. C. Português: Linguagens. São Paulo: Saraiva, 2013, pp. 417-420.

CLARK, Katerina \& HOLQUIST, Michel. Mikhail Bakhtin. São Paulo, Perspectiva, 1998.

DOLZ J.; SCHNEUWLY, B. Pour un enseignement de l'oral. Initiation aux genres formels à l'école. Paris: Esf, 1998.

FARACO, C. A. 'Voloshinov: um coração humboldtiano?' In: FARACO, C. A. et al. (eds.), Vinte ensaios sobre Mikhail Bakhtin. Petrópolis, Rio de Janeiro: Vozes, 2006, pp.125-126.

FARACO, C. A. Linguagem \&diálogo: as ideias linguísticas do círculo de Bakhtin. São Paulo: Parábola, 2009, p.15.

GOMES-SANTOS, S. A questão do gênero no Brasil: Teorização acadêmico-científica e normatização oficial Doctorate thesis. Campinas, Language Studies Institute, State University of Campinas/Unicamp, 2004, p. 152.

HOLQUIST, M.; LIAPUNOV, V. Art and answerability: Early Philosophical Essays by M.M. Bakhtin. Austin: University of Texas Press, 1990.

RODRIGUES, R. H. Os gêneros do discurso na perspectiva dialógica da linguagem: a abordagem de Bakhtin. In: MEURER, J. L. et al. (eds.), Gêneros: teorias, métodos, debates São Paulo: Parábola, 2005, pp.184-207.

ROJO, R. Gêneros do discurso e gêneros textuais: questões teóricas e aplicadas. In: MEURER, J. L. et al. (eds.), Gêneros: teorias, métodos, debates. São Paulo: Parábola, 2005, pp.184-207.

ROJO, R. Gêneros de discurso/texto como objeto de ensino de línguas: um retorno ao trivium? In SIGNORINI, I. [Re]discutir texto, gênero e discurso. São Paulo: Parábola, 2008, pp.73-108. 
SOUZA, G. T. Introdução à teoria do enunciado concreto do círculo Bakhtin/

Volochinov/Medvedev. São Paulo: Humanitas, 1999, p. 42.

VISIOLI, A. C. C. Política de ensino de língua portuguesa e prática docente. Masters Dissertation. Maringá-Paraná: UEM, 2004, p. 32.

VOLOŠINOV, V. N. Marxism and the Philosophy of Language. Trans. by L. Matejka;

I.R.Titunik. Cambridge, Massachusetts: Harvard University Press, 1973. 